\title{
JOSÉ IGNACIO CABRUJAS: \\ LA MUERTE DE LA TELENOVELA
}

\author{
POR \\ NeLSON HIPPOLYTE \\ University of Pittsburgh
}

José Ignacio Cabrujas (1937-1995): dramaturgo, director, actor, articulista, profesor universitario, y guionista de radio, cine y televisión. Isaac Chocrón al referirse al carácter polifacético de José Ignacio Cabrujas como dramaturgo, director y actor dijo hace treinta años que era sobresaliente en todas ellas hasta el punto en que resultaba controversial jerarquizárselas. Hoy en día esa controversia se problematizaría más aún si tomamos en cuenta sus otras vertientes creativas. José Ignacio Cabrujas fue el maestro, como solían llamarlo sus amigos, un hombre con la visión totalizadora de los ensayistas del siglo diecinueve y la complejidad del hombre del siglo veinte. Entre sus obras de teatro se cuentan: Los insurgentes (1956), Juan Francisco León (1959), El extraño viaje de Simón el malo (1961), Tradicional hospitalidad (1962); En nombre del Rey (1963), Días de poder (1964), Fiésole (1968), Profundo (1971), Acto cultural (1976), El día que me quieras (1979), Una noche oriental (1983), El americano ilustrado (1986) y Autorretrato de un artista con barba y pumpá (1990). Como autor de telenovelas cambió la historia del género en Venezuela: La señora de Cárdenas (1977), Silvia Rivas, divorciada (1977), Soltera y sin compromiso (1978), La dueña (1985), La dama de rosa (1986), Señora (1988), Emperatriz (1990), Las dos Dianas (1992) y El paseo de la gracia de Dios (1992). Sus artículos de prensa para los diarios "El Nacional" y "El Diario de Caracas" se cuentan por decenas. Todos ellos reflejaron "el descontento frente a los políticos, las instituciones y la manera como se ha conducido al país". Su particular estilo, una equilibrada mezcla de crítica, humor e ironía, hizo que su pluma fuese una de las más respetadas del país.

La Revista Iberoamericana en reconocimiento del talento y obra de este escritor venezolano, publica un extracto de la conversación informal que sostuvo con Nelson Hippolyte en julio de 1993, sobre la telenovela venezolana, para su tesis de doctorado Señora Culebrón (El folletín electrónico en Venezuela 1953-1995).

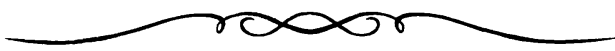

NELSON HIPPOLYTE: ¿Para qué sirven las telenovelas?

JOSÉ IGNACIO CABRUJAS: ¿Para qué sirve una ficción? Para que las personas adquieran un sentido superior de su vida, para que la gente se sienta mejor, representada dignamente ... Ahora, fines prácticos, ninguno. ¡Claro! la telenovela puede tener fines prácticos 
secundarios y es bueno usarlos, la lógica lo dice en Latinoamérica, un continente atormentado por problemas donde habría que decir algo, entonces, sí como no, sirvió —como pasó en España con Cristal de la señora Fiallo- para que se redujera el porcentaje de cáncer mamario, un dato absolutamente concreto: la señora Fiallo logró reducir el cáncer mamario en un 20 por ciento, introduciendo esa trama en su novela. Pero ese es un espejismo que me parece desvirtuante de la propia telenovela. Hace poco UNICEF me invitó para plantearme los problemas de niños latinoamericanos y de cómo se podía hacer para insertarlos dentro de una telenovela. Yo descubrí allí una ingenuidad: ¿es que ellos creen que una telenovela puede hacer el milagro de que los niños latinoamericanos marchen bien o de que por lo menos se reduzcan sus problemas? Eso es una tontería. Una telenovela sirve para lo que puede servir cualquier obra de carácter literario: para provocar la imagen que tiene el ser humano de sí mismo; una sociedad de sí misma.

\section{N.H: Los intelectuales españoles pareceria que no le tienen ningún respeto.}

J.I.C.: Ese estamento de señores considera que la telenovela es una cosa abominable sin hacer ningún matiz, sin decir déjame ver ésta en relación a ésta; no, no, no, para ellos eso es malo porque intelectualmente es indigno "para las señoras mediocres españolas que la ven". Ése es un rollo al cual no le presto mucha atención porque es un problema antropológico, es un concepto de antropología cultural, aquél que plantea que existe un arte sublime y un arte mediocre, y la vida se ve en términos de buen gusto y de mal gusto. ¿Quién dice que Picasso es el pintor más grande del siglo XX? El uno por ciento de la humanidad dice eso, y lo consagra como el gran pintor, pero el 99 por ciento restante no lo ve, no le interesa, no lo apreciay en muchas ocasiones lo detesta y dice que es un mal pintor. Entonces es un tema que no se puede resolver y no se puede resolver por esto: si tú eres un intelectual, en efecto, has hecho una larga inversión de tu tiempo en tu método de vida, en tu organización, para convertirte en un "hombre superior" y para no reaccionar al igual que el populacho. Si Wagner Bross hace Batman y tú eres un filósofo, dirás que ése es un producto deleznable, dices que cine es Igmar Bergman no Batman. Frente a ese problema los gringos son los que se exceptúan de ese drama en el mundo. Yo lo leí en un libro de un antropólogo gringo sobre el problema de la cultura popular en los Estados Unidos; un país que ha generado una cultura con un acento distinto frente a la cultura europea. Liza Minnelli es igual que Leonard Bernstein en los Estados Unidos, exactamente igual, los dos van a ser invitados a la Casa Blanca; el más severo intelectual de ese país va a decir "Liza Minnelli, usted es una maravilla" y "señor Bernstein, usted es una maravilla". Los americanos están orgullosos de su música popular, la consideran el desideratum de la música. Ahora en Latinoamérica la cantante popular venezolana Lila Morillo no es nadie, Lila Morillo no tiene cédula en el sector intelectual, es una cursi, una ridícula y una manipuladora; en efecto, esto es porque la cultura popular nuestra es como "pobrecita", nosotros la hacemos pobre. Fíjate en este ejemplo: hace unos años se reinaguró la Estatua de la Libertad, yo vi la trasmisión vía satélite, reflexioné sobre el asunto y comenté: si los venezolanos tuviéramos una Estatua de la Libertad, algo así equivalente que nos regalara el gobierno de Francia y de la cual nos sintiéramos orgullosísimos, y para su centenario, la arreglamos e invitamos a Mitterand, ¿qué haríamos los venezolanos? La octava sinfonía de Mahler con la Orquesta Simón Bolivar y un coro de 500 voces, porque eso nos parecería lo más cónsono y ejemplar, para que Mitterand diga: "estos carajos están en una vaina". O presentamos algo folklórico, 
folklórico como el indio Figueredo. La respuesta de los gringos es distinta: te hacen un recital donde como no estaba Leonard Bernstein, te presentan a Gene Kelly y ese actor, viejo ya, hace los pasitos de Singing in the Rain, y los gringos lloran, Mitterand llora, la humanidad se desborda; pero eso no es mejor que una telenovela. El espectáculo culmina con Liza Minnelli cantando New York, New York, y todo el mundo, vuela. Entonces, ves la Estatua de la Libertad, la muchedumbre de gringos y el paquete es completico. Tú sacas aquí a Lila Morillo en la re-inauguración de la Estatua de Bolívar y detona, explota, colapsa; es decir, no tiene el mismo significado porque la muchedumbre que podría amar a Lila, no tiene acceso a consagrarla como un valor glamoroso de la sociedad.

N.H.: Durante la dictadura de Pérez Jiménez, hace 35 años, como que sí se logró con la cantante de joropos Magdalena Sánchez. La llevaban a las inauguraciones oficiales y era un gran suceso.

J.I.C.: Yo estoy por pensar que Pérez Jiménez fue un gran gobernante en esos aspectos. Asumió con dignidad la vida del país, no quiso trastocar aquellos valores que estaban extendidos dentro de la sociedad venezolana, y constituían una proyección orgullosa de las personas. Eso no continuó. El problema de la cultura en Venezuela sería un tema de un gran análisis. Por ejemplo, ¿cuál es la crítica que se le hace a la telenovela? Que es estúpida, cursi ... Hay sectores del intelecto que la ven con una sonrisita. Yo conozco a algunos intelectuales que ven telenovelas y te dicen: "que bien estuvo ayer ese capítulo". Pero nunca los verás emocionados, lo que perciben es el juego tuyo, la pericia tuya, el humor ... ¿Qué diablos puedes decir a eso? ¿Qué importa? Tú no estás escribiendo para esa gente. El gran dilema de una persona que hace telenovelas es insertarse en un mundo que es brutalmente real y asumir esa cultura que es una cultura chocante para el "elevado"; el "elevado" sufre, un Adriano González León debe morir porque si a ti te gusta Mallarmé y consideras que eso es lo más grande que ha habido, entonces, claro, una cosa de la señora Fiallo te debe parecer algo monstruoso. Tú hablas con Antonio Pasquali, y te dice: "es bueno mejorar la telenovela para que la gente pueda ver a Ionesco". Eso me lo dijo a mí, en mi cara; es decir, que la meta cultural de Antonio Pasquali es que la gente vea a Ionesco, por lo tanto, mejora tú podredumbre para que le des un escaloncito a esto, porque cuando tú ves a Ionesco, te salvaste en la vida, te rescataste. Es el eterno problema de considerar que Beethoven es mejor compositor que Tito Curé Alonso. No, coño, no. Raúl Amundaray me comentaba, hablándome de un actor: "él es muy bueno en su género". Yo escribí la misma frase: Beethoven es muy bueno en su género. Tito Curé es muy bueno en su género. ¿Y por qué los dos no pueden convivir?

Juan Gabriel, por ejemplo, es un ser cercano a ser un genio cuando interpreta algunas canciones clásicas mexicanas; nunca lo hace, pero a Venevisión mandó un video de un recital suyo donde su interpretación no podía ser mejor: era un arte. Entonces tú dices: es un genio, pero no termina de ser Liza Minnelli, es un problema nuestro. A lo mejor el error está en tratar de compararlo; de lo que se trata es del empaque del show, de la cultura del espectáculo que tiene la nación norteamericana, que, por supuesto, México dista mucho de tener. Pero en todo caso tú estás escuchando a un subdesarrollado latinoamericano y es como morboso, como pecaminoso que te guste.

N.H.: La telenovela padece de cierto anacronismo ¿De dónde salió que tenia que girar en torno de la muchacha de campo, el ascenso social, el villano ...? 
J.I.C.: Ése es un tema latinoamericano de finales del siglo XIX. Si analizas por un momento toda la tradición del teatro popular latinoamericano, autores como Florencio Sánchez en el Río de la Plata, autores como Rafael Guinand en Venezuela, te darás cuenta de que el tema era casi siempre el hombre o la muchacha ingenua o el campesino engañado por el hombre de la ciudad; ése es un tema muy querido por el universo latinoamericano. Hay quien piensa que podría venir del Barroco, pero en todo caso si vuelves a pasearte por la novelística de Rómulo Gallegos, muy disfrazada de mensaje social y de etcétera, vas a encontrar al hombre civilizador y a la muchachita pobre, como en Doña Bárbara, y también vas a encontrarlo en María de Jorge Isaac, en Peonía .... Son temas latinoamericanos, incluso si nos pusiéramos a meditar un poco sobre el porqué son tan queridos, llegaríamos a la conclusión de que se parecen a la sociedad latinoamericana, la desconfianza del hombre culto, la desconfianza del poderoso, un pueblo oprimido, arrinconado, que ve en el poder, en el dinero, ve en la cultura, incluso, una amenaza.

N.H.: Y el amor siempre es el tema central del género.

J.I.C.: El hombre tiene unas características muy raras como lector a través de toda la cultura humana de Occidente: las únicas historias populares de la gran literatura son historias de amor; en realidad, no se ha escrito nada que le haya importado a la gente, me refiero a la gran literatura, que no sea una historia de amor. La guerra y la paz es un ejemplo. En una cátedra universitaria tu podrás decir que allí hay una reflexión sobre el pensamiento liberal y sobre el nuevo hombre post-revolucionario, entre muchas cosas... Pero, ¿qué hace a esa novela sobrecogedora? ¿Por qué el lector no puede abandonar su lectura? Por aquello de que ... él la quiere a ella, y ella se casa con otro. Ése es el problema. Sobre esa autopista, Tolstoy inserta genialmente un universo filosófico y conceptual enorme, profundo, que sería una pena que el lector no lo tomara en cuenta. Cuando la $B B C$ de Londres comenzó la trasmisión de La guerra y la paz, en Yugoslavia, yo la veía mordiéndome las uñas y maravillado. Lo que estaba viendo era una historia de amor, y sólo esperaba que él la volviera a encontrar a ella. Para los hombres todo lo que es largo tiene que ser amor. La Ilíada es de amor y la Odisea mucho más. Esos "chorizos" que los hombres han creado obras monumentales-son, en realidad, historias de amor. Parece mentira, pero no hay otra cosa que instale a persona a ver una cosa todos los días, y durante diez meses y doscientas horas de su vida.

N.H.: En alguna oportunidad acusaste a las telenovelas de pacatas porque no se podian trastocar los valores sociales, $y$, por otra parte, habian realidades que no se mostraban. ¿Sigues de acuerdo con ese planteamiento?

J.I.C.: No, creo que no. No me reconozco a mí mismo diciendo eso. Si la única obligación que tiene un arte cualquiera es trastocar los valores sociales. Lo que sí recuerdo haber dicho es que la masificación de la telenovela, y por ende del medio televisivo, nos impone ciertas prudencias ante afirmaciones o contenidos que provienen de otras estructuras artísticas. Siempre he citado un ejemplo de un famoso monólogo de Shakespeare sobre el vino, en el cual mediante una forma poética se exalta el valor de que te emborraches como algo extraordinario, elevadísimo. Es posible que si logras traducir eso a un lenguaje popular y hacerlo tan impactante como pudo haber sido en su época ese lenguaje de Shakespeare y lo reproduces y catapultas para diez millones de personas, posiblemente terminarías creando una publicidad que favorece al alcoholismo. La televisión tiene una idea de lo que es el 
sentido público. Hay algo que la emparenta al cuerpo de bomberos, es demasiado masiva, como son los bomberos. El televisor se enciende en la casa con una alegría irresponsable, lo están viendo niños, lo están viendo viejos, o sea, todo el mundo; ... entonces debes imaginar quién te está viendo. La televisión tiene que tener un lenguaje cívico, eso forma parte de lo que yo llamo la humildad de la televisión. En ese sentido el artista tiene que ser humilde, entender que su lenguaje, por primera vez, se traduce en términos muy reales, por lo tanto no puedes estar diciendo disparates. Escuché hace poco un poema de un tipo que le dio SIDA, lo leí en una revista americana donde el tipo decía: "me sabe a soda que me de un sida, pues. Lo pasé bien y lo asumo". Bueno, magnífico. Yo lo creo y digo ¡qué palo de tipo!, pero yo no puedo decir eso por televisión: coño me dió SIDA y para el carajo, no, porque cae en un universo brutalmente amplio. Para los lectores del poema esa señal pudiera derivar en un acto poético, en un acto violento de rebeldía, pero existe un gran porcentaje de la sociedad para quien eso no deriva en rebeldía sino en un aprendizaje. Yo nunca he tenido esos valores de que éste es bueno y éste es malo, yo todavía desprecio esos valores, pero cuando la televisión los coloca, me he acostumbrado a que mucha gente espera de ti algo ... la palabra es horrible ... constructivo. Yo me he acostumbrado a respetar esa palabra en la televisión.

N.H.: ¿Qué diferencia encuentras entre la telenovela de los años sesenta y la de los noventa?

J.I.C.: La diferencia tecnológica, de mayor realidad del género. Paulatinamente, ha ido conquistando una mayor realidad, ése es un proceso importante para analizar. La telenovela ha conquistado primero su propia autenticidad. Los que hemos escrito telenovelas a lo largo de ese escribir, nos hemos dado cuenta de algo: la telenovela existe como un género con unas características. El problema no está en alterar el género a fin de negarlo, sino en encontrar dentro de él su propio rescate, su propia trascendencia e importancia que lo catapulte como un gran género. Ése ha sido quizás el enigma, la tentación, el no sé, el espejismo, quizás. Estoy convencido de eso. Cuando yo escribí La dueña, me convencí de que una telenovela culebrónica vale la pena; es decir, que el sustituto de la telenovela no puede ser el realismo, el realismo es una cosa absolutamente disparatada en la telenovela. Ésta se puede salvar, si ese es el caso, y si podemos utilizar esa palabra que me cuesta usarla ... bueno, enaltecer, subir, elevar — diría - siempre y cuando sea fiel a sí misma, siempre y cuando no quiera introducir elementos que la desvirtúen, siempre y cuando no me avergüence el género. Hay una necesidad impostergable en el escritor de telenovelas del futuro, de entender que eso es la telenovela y aceptarla con cierta humildad, como es. Voy a utilizar recursos del melodrama, voy a utilizar recursos que provienen del siglo XIX, voy a utilizar unas peripecias, voy a utilizar algo que es muy deleznable para quien piensa la narrativa en términos realistas. La telenovela no se puede salvar por el realismo, la telenovela se puede salvar y se puede engrandecer y dignificar y llegar a extremos extraordinarios, a mi criterio, por Shakespeare, por Sófocles, por los griegos, no por el realismo. La telenovela es un delirio de la conducta. Si yo tuviera que definirla, utilizaría una palabra muy gringa porque no encuentro otra: la telenovela es el show del sentimiento, y no un espectáculo porque le temo a esa palabra en español. Espectáculo no es igual que show. Show es una confabulación de factores, de técnicas, de luces, de colorido, que sobre un acontecimiento, por ejemplo de tipo musical ocurre. Todos hemos visto un show de Sting 
por situar un valor de nuestra época. Si redujéramos a Sting a un realismo, ¿qué sería? Un señor con una precaria voz, muy vergonzosa voz. Imaginemos que lo tenemos sentado en esta sala donde estamos tú y yo hablando. ¿Que sería? Un señor que toca tímidamente esa guitarra y canta muy precariamente unas canciones; ése no es el Sting que tú y yo conocemos cuando lo vemos en un video donde su imagen, su voz y su guitarra son ultra amplificadas. De repente empiezan a funcionar pantallas gigantescas, su imagen se fragmenta, aparecen rayos láser y una cantidad de empaques sonoros, visuales y de entorno que logran que Sting se pueda catapultar como una figura moderna casi post-romántica, impetuosa, a tono con lo que el hombre de hoy en día considera una gran cosa, un gran acontecimiento. La telenovela participa de ese fenómeno. En la modesta fisonomía latinoamericana, ella trata de engrandecer, catapultar, exagerar, hiperbolizar un sentimiento, a fin de hacerlos absolutamente drásticos y perturbadores ante la masa. ¿Cómo se puede creer que una persona prende la televisión para ver la realidad? ¿Cómo se puede creer que un espectáculo de ficción sustituye a un noticiero? Eso es absurdo. Hoy en día hay noticieros lo suficientemente melodramáticos, convincentes para mostrarnos una noticia desgarradora en lo sentimental, en lo emotivo. La telenovela podría enfocar la realidad como lo decíamos la otra vez, como una textura, como un detalle, como un estilo, pero al fin de cuentas las características en sí de la historia determinan grandes acontecimientos. Todo en la cultura moderna, en la cultura audiovisual, incita a los grandes acontecimientos. ¿Quién hace televisión con los pequeños? Nadie. Son programas menores, subalternos que renuncian a la masa. Hay una desesperada necesidad en nuestro mundo del gran acontecimiento; es decir, los que vimos en televisión los cohetes norteamericanos en Bagdad ... ¿estuvimos presenciando qué? ¿una guerra? Para un hombre como yo eso no era una guerra, era un show tecnológico de la industria militar norteamericana y, a la vez, era un acontecimiento dramático frente a nuestros ojos. Se estaban produciendo unas muertes anónimas en esa especie de Nintendo; estábamos viendo morir personas, lo que no vimos cuando éramos niños durante la Segunda Guerra Mundial. En aquél entonces mirábamos una imagen fraccionada, unos cohetes que caían, unas bombas, unos disparos. Pero aquí CNN estaba transportando la vida, hoy pasa, ahora pasa. Por lo tanto dentro de esa estructura mental, donde un show musical tiene que ser lo nunca visto, lo nunca oído, no tiene sentido. Cuando uno va a escuchar - hablando en términos gringos-a Madonna, por ejemplo, ¿cuándo la vamos a escuchar en sus límites? Nunca. Madonna cada vez que hace un espectáculo para televisión, del cual se va a derivar un video, un video láser, o un disco compacto, hace algo único, irrepetible, definitivo. Madonna en la intimidad con una guitarrita, en sus propios límites... imagínatela ... sólo por vía de excepción, que ya es un espectáculo. Entonces, decir en este instante la gran Madonna se reduce a este límite, es un momento reconocible, es un momento perdurable. Cuando la telenovela entra dentro de los límites del actual lenguaje audiovisual, debería mostrar lo nunca visto, por lo tanto el que hable de realismo, ¿qué está diciendo?, ¿qué significa eso? ¿qué es eso en la cultura de masas?, ¿qué es el realismo ante los hombres que ven televisión? Nada. La cuota de realismo que tienes en televisión es que el dólar amaneció a tantos bolívares o que el Dow-Jones se cayó en tal y cual porcentaje.

N.H.: El género de la telenevela se muestra camaleónico, con una dinámica de avances y retrocesos. Por ejemplo, en la década del setenta ustedes lo renovaron y de repente en la década siguiente se regresó a la telenovela tradicional. En los noventa se 
produjo una ruptura con Por estas calles, y ahora se regresa a los clichés de siempre. Eso es preocupante, ¿no?

J.I.C.: Tienes toda la razón, igual sucede en el cine, o en la comedia musical norteamericana, o en los campos de tipo masivo y comercial, en efecto se camaleoniza. Pregúntate por una cosa tan simplona y tan contundente como el Fantasma de la ópera en Broadway: ¿responde a una temática contemporánea?, ¿a qué diablos responde?, ¿por qué la gente se vuelca a ver ese espectáculo? Porque es una visión renovada en el empaque del género de la comedia musical; es decir, la gente percibe un gran espectáculo con una cantidad de innovaciones. La gente no se mueve por decisiones intelectuales, el público que consume una cultura no se mueve por eso, se mueve por nociones de éxito, de que esto tiene éxito y esto simplemente se asocia a lo standard, a lo establecido; pero rápidamente las cosas tienen que ser renovadas. Muchas veces pensamos que renovar es una cosa como la que hizo Joyce cuando escribió Ulises; ésa es una renovación drástica que naturalmente condena a un libro como Ulises a ser un inmenso fracaso editorial ¿no?, y a no ser percibido sino por ocho personas; a ser uno de esos orgullosos fracasos de los cuales está lleno la literatura. Todavía a estas alturas el Ulises no es un libro que abunde, ni que siquiera interese. Es que nosotros estamos hablando de una cosa que se llama cultura de masas, que no tiene nada que ver con sus parámetros. Su manera de conducirse y de comportarse es muchísimo más lenta porque a su vez es más amplia y más gruesa. Entonces, es un enorme error pensar en una dinámica intelectual cuando se piensa en televisión, ni aún en la mejor televisión del mundo. Por lo tanto, si tú programa no es consumido masivamente no tiene ninguna posibilidad de subsistencia; entonces, lo que sucede allí desconcierta al crítico que quiere aplicar medidas que forman parte de la historia del arte, de la historia del pensamiento ... Cuando el espectáculo de televisión conquista algo que suena a modernización, actualización, eso ha sido el producto de una batalla campal, que ha logrado triunfar sobre intereses gigantescos.

N.H.: Todo ese agotamiento temático, la repetición de las mismas tramas, el no saber hacia dónde va el género, me hace pensar en la "muerte de la telenovela".

J.I.C.: Yo creo que esta historia de amor sentimental y cursilona, Latinoamérica la ha empezado como a abandonar, hay un hambre de modernidad en el continente. Yo lo veo, Latinoamérica a fin de cuentas ha empezado a disfrutar otras instancias, ha habido un desarrollo, este continente no es el mismo de cuando yo tenía quince años. Entonces la gente quiere más; a la gente, por ejemplo, le molesta que la telenovela sea todos los días lo mismo. Los muchachos de dieciocho y veinte años quisieran una televisión distinta, quisieran verse ellos, quisieran una televisión más inquietante, con programas más polémicos, más versátiles, menos modulares. La telenovela es lo más modular que existe, demasiado modular, y eso empieza a conspirar contra ella. Yo ví una encuesta que hizo el Canal Siete de Nueva York bien desoladora donde la gente de veinte años piensa que la telenovela es una vaina de la abuelita de ellos, y tan pronto se muera la abuelita, desparecerá. Identifican la telenovela con el oscuro pasado latinoamericano, con la pobreza, y les trae malos recuerdos. La telenovela se comporta muy fuerte en sociedades cuyo acceso a otras fórmulas de cultura está vedado. Por ejemplo, una novela mía, La dos Dianas, rompió todos los records de la televisión panameña, pero a mí me problematiza mucho decirlo porque lo que está pasando es que la telenovela hereda una respuesta muy auténtica del continente ante la necesidad de verse presentado. En Latinoamérica no hay un cine y la literatura 
latinoamericana es virtual, no es real, sólo la telenovela. Es el único relato latinoamericano, pero ella ha comenzado a irse hacia otro módulo, los brasileños son los que han marcado ese paso a finales de los setenta y han continuado hasta los noventa; ellos han ido enrareciendo la telenovela cada día más. Creo-yo he visto algunas telenovelas brasileñasque la telenovela de ese país va a ser sustituida por un tipo de programación dramática que en el fondo va a recordar a la telenovela pero que en realidad va a ser un cambio absoluto de ella misma. Y eso es lo que yo creo que aquí no tardará. El desconcierto que hay hoy en día para producir una telenovela es tremendo. Venevisión es una empresa paralizada en vida, por eso no se atreve a hacer una telenovela. Una cosa que se supone que ellos dominaban y entendían, y ahorita cuando los ves reunidos están perdidos, perdidos. Saben que algo pasó, entonces ven a Arquímedes, el pobre, que es el que se supone que representa la telenovela allí y entonces, claro, le hacen buches, no quieren saber de él. Han perdido el norte de la telenovela por completo porque todas las telenovelas de hoy en día tienden a ser raras para poder subsistir. Dulce ilusión, la novela de Marielita Romero, introdujo unos personajes de caricatura, algo nada ortodoxo dentro del género, pero ésa es una mala noticia para la telenovela porque no estamos viendo precisamente a Roger Rabbitt. No es una conquista que tú digas, se trata de una cosa precaria; sin embargo, el público la ve por eso.

N.H.: Al menos, las lágrimas han ido desapareciendo de los culebrones.

J.I.C.: Las banales sí, no las lágrimas, porque es muy sabroso que la gente llore en una telenovela y se tome la vida a pecho y se tome sus conflictos a pecho. Es muy importante, la gente quiere ver algo sublime. Yo te decía la otra vez que la nueva tendencia de las telenovelas que se realicen tiene que partir de una emoción. Nadie anda ya en ese problema "zamurero"; ya no se trata de telenovelas de ciegüitas, eso de verdad ya no se está haciendo, es decir, podrán quedar algunas por allí pero están condenadas a muerte. Eso cambió, indiscutiblemente cambió. Ahora, el problema sigue siendo una historia de amor. La televisión brasileña ha manejado la realidad respetando el centro de una historia de amor como fundamento, entonces ha tratado de crear un mayor acercamiento hacia la realidad, hacia los personajes menores, hacia temas no trillados. Yo creo que los brasileños han impuesto eso, aunque aquí a los fabricantes de telenovelas les duela reconocerlo. Sus enemigos son los brasileños.

N.H.: ¿Qué buscas reflejar en tus telenovelas? ¿Tu condición de hombre de clase media?

J.I.C.: Sí, quiero reflejarme a mí mismo, mis sensibilidades, mis opiniones; quiero reflejar la dignidad - ése es un tema que me obsesiona a mí- la dignidad de la gente. Quiero contar la historia de dignidades y no de enseñanzas. Me importan algunos símbolos que en esta sociedad son efectivos y emocionantes: la solidaridad. Supongo que lo que más tengo dentro de mí cuando quiero escribir una telenovela es decir con orgullo: ¡Somos gente estupenda!

N.H.: "El fracaso" si es que se puede llamar "fracaso" de El paseo de la gracia de Dios, precisamente por no tener el rating de Por estas calles te hizo decir en privado: "No quiero quedar como la abuelita de las telenovelas” ¿Qué significa eso?

J.I.C.: Que no quiero quedar como el tipo que trató de hacer pervivir un género ... de verdad que no tiene sentido, son razones ya mías, de mi propia vida, pero ¡vamos! con esta novela termino un ciclo de mi vida, no sólo el ciclo de la telenovela, un ciclo de mi vida. 
A mí no me gusta fracasar, yo le tengo pánico a esa palabra. Para mí la telenovela se me está transformando en un fracaso, en un fracaso. Yo no te estoy diciendo se acabó la telenovela para mí, no; al mismo tiempo he dicho a quien me ha querido oír que ésta es mi última telenovela. Y a lo mejor es verdad y nunca más hago otra, pero si hago otra es porque encontraré una manera de hacerla y una circunstancia de producción para hacerla absolutamente distinta a la de este momento. Es un discurso que tengo que meditar, no es fácil, tengo que ir contra mí mismo, contra vicios, contra hábitos, contra un know how que yo tengo de la telenovela. Ponerlo en el cesto de la basura, que es lo que quiero y no es fácil. Nada se pone fácilmente en la basura, pero necesito hacerlo porque no tiene sentido; es decir, una cosa que me doy cuenta que sería ya muy deshonesto conmigo mismo, me doy cuenta que eso está muriendo, muriendo ... 
